\title{
Novel Immunity Proteins Associated with Colicin M-like Bacteriocins Exhibit Promiscuous Protection in Pseudomonas
}

\author{
Maarten G. K. Ghequire ${ }^{1,2 *}$, Lieselore Kemland ${ }^{1}$ and René De Mot ${ }^{1}$ \\ ${ }^{1}$ Centre of Microbial and Plant Genetics, KU Leuven, Heverlee, Belgium, ${ }^{2}$ National Institute of Diabetes and Digestive and \\ Kidney Diseases, National Institutes of Health, Bethesda, MD, USA
}

OPEN ACCESS

Edited by:

Michael Thomas-Poulsen,

University of Copenhagen, Denmark

Reviewed by:

Pierre Cornelis,

Vrije Universiteit Brussel, Belgium

Kevin Loren Hockett,

University of Arizona, USA

*Correspondence:

Maarten G. K. Ghequire maarten.ghequire@biw.kuleuven.be

Specialty section:

This article was submitted to Antimicrobials, Resistance and Chemotherapy,

a section of the journal Frontiers in Microbiology

Received: 18 July 2016 Accepted: 13 January 2017 Published: 30 January 2017

Citation:

Ghequire MGK, Kemland $L$ and $D e$ Mot $R$ (2017) Novel Immunity Proteins

Associated with Colicin M-like

Bacteriocins Exhibit Promiscuous Protection in Pseudomonas.

Front. Microbiol. 8:93.

doi: 10.3389/fmicb.2017.00093
Bacteriocins related to colicin $\mathrm{M}$, acting via cleavage of the cell wall precursor lipid $I$, have been characterized in $\gamma$ - and $\beta$-proteobacteria. Depending on the species, immunity is provided by either an inner membrane-anchored periplasmic protein or by an integral membrane protein. In Pseudomonas however, the immunity partner of colicin M-like bacteriocins remains unknown. Based on an in silico analysis in pseudomonad genomes, we here identify a gene encoding a putative immunity partner that represents a novel type of integral membrane protein (PmiA, Pseudomonas colicin M-like immunity type A). By heterologous expression of pmiA genes in susceptible strains, we show that immunity to colicin M-like bacteriocins is indeed provided by the cognate PmiA. Sequence homology among PmiA proteins is essentially absent, except for a short motif with a conserved periplasm-exposed aspartate residue. However, PmiA's protective function is not abolished by changing this acidic residue to the uncharged alanine. Immunity by PmiAs appears promiscuous to the extent that PmiA homologs from a clade sharing $<40 \%$ pairwise amino acid identity, equally provide protection against the bacteriocin linked to the original PmiA. This study shows that multiple immunity factors have evolved independently to silence lipid II-targeting enzymatic bacteriocins. Their relaxed bacteriocin immunization capacity contrasts to the strict specificity of immunity proteins shielding the enzymatic domain of nuclease bacteriocins. The nature of associated immune functions needs consideration when using such natural protein antibiotics or designing novel variants.

Keywords: colicin M, PmiA, PmiB, pyocin, peptidoglycan, lipid II

\section{INTRODUCTION}

Antibacterial proteins are currently subject of renewed interest in the search for antimicrobials with novel modes of action. As yet poorly explored potential sources of such alternative protein-based antibiotics include lytic bacteriophages (Gerstmans et al., 2016) and bacteriocinogenic strains (Schulz et al., 2015). Bacteriocins are key mediators of intra-species competition between bacteria and combine high specificity with single-hit killing potency. Prominent bacteriocin producers that target human and plant pathogenic Gram-negative bacteria are found among enterobacteria (Cascales et al., 2007; Holt et al., 2013; Grinter et al., 2014; Schulz et al., 2015) and pseudomonads (Ghequire and De Mot, 2014). 
Pseudomonas bacteriocins are very diverse with respect to structure and mode of action. R-type and F-type tailocins are multiprotein complexes that are evolutionary related to bacteriophage tails (Ghequire and De Mot, 2015a; Ghequire et al., 2015; Hockett et al., 2015). Lectin-like bacteriocins are constituted of a tandem of monocot mannose-binding lectin domains, and kill target cells via an unknown mechanism (Ghequire et al., 2013, 2014; McCaughey et al., 2014). Stype bacteriocins are multi-domain toxins with a modular structure similar to colicins, the bacteriocins from Escherichia coli (Cascales et al., 2007; Ghequire and De Mot, 2014; Dingemans et al., 2016; McCaughey et al., 2016). Selfinhibition of Pseudomonas aeruginosa strains producing a Stype bacteriocin ( $\mathrm{S}$ pyocin) is circumvented by an immunity protein that transiently impedes the bacteriocin's toxic function. This immunity complement is co-expressed with the bacteriocin, and is typically encoded downstream of the pyocin gene, on the same or opposite strand. In the case of S-type bacteriocins with nuclease activity, bacteriocins are secreted as high-affinity bacteriocin-immunity protein complexes (Joshi et al., 2015). Pseudomonas colicin M-like bacteriocins (PseuMs) host a lipid IIcleaving domain, homologous to the catalytic domain of colicin M (ColM; Barreteau et al., 2009, 2012; Grinter et al., 2012b). However, in contrast to $S$ pyocin-immunity complexes, it is not clear how PseuM producers protect themselves. Inspection of their pseuM genomic context did not reveal homologs of $\mathrm{cmi}$, the cognate immunity partner for ColM in E. coli, nor were such homologs detected elsewhere in their genomes (Barreteau et al., 2009).

In E. coli, the cmi gene is located downstream of the bacteriocin gene on the opposite strand (Olschläger et al., 1984; Olschläger and Braun, 1987). Located in the periplasm, Cmi is anchored to the inner membrane by an amino-terminal hydrophobic $\alpha$-helix, assisting in secretion but not being cleaved off. There, Cmi transiently impedes colicin M's activity during secretion and inactivates imported ColM (Olschläger and Braun, 1987; Olschläger et al., 1991; Gross and Braun, 1996). The crystal structure of $\mathrm{Cmi}$ revealed the presence of four $\alpha$-helices and four $\beta$-strands, and is exemplary of a YebF fold (Gérard et al., 2011; Usón et al., 2012). In Pectobacterium a cmi-like gene is located downstream and opposite of the pectocin $M$ gene, but its protective functionality remains to be demonstrated (Grinter et al., 2012a). In most strains of Burkholderia producing colicin M-like burkhocins, immunity is mediated by $b m i B$ genes that give rise to proteins with a small size and predicted topology similar to Cmi (Ghequire and De Mot, 2015b). However, the amino acid sequence of the periplasmic moiety of $\mathrm{BmiB}$ is unrelated to $\mathrm{Cmi}$ and lacks the characteristic YebF domain. Fewer strains carry a second type of burkhocin immunity gene $(b m i A)$ that encodes a small integral membrane protein comprising three transmembrane helices.

In this study we investigated the genomic context of pseuM genes, in search for candidate immunity partners. We demonstrate that a gene downstream of $p s e u M$ provides cognate immunity. Apart from sharing a common membrane topology reminiscent of BmiA proteins, the encoded proteins display very poor sequence conservation across PseuM-bacteriocinogenic pseudomonads. The possible role of a short semi-conserved motif in these proteins is explored, as well as the capability of PmiA proteins to immunize targeted cells in an (a)specific way.

\section{MATERIALS AND METHODS}

\section{Genome Searches and Phylogenetic Analysis}

PseuM bacteriocin genes in Pseudomonas genomes were identified by homology searches using the National Center for Biotechnology (NCBI) non-redundant database. The Pfam Colicin_M module PF14859 was used as a query. Genes downstream of unique pseuM bacteriocin gene products were selected for further analysis. Multiple sequence alignments were generated with MUSCLE and phylogenetic reconstructions were carried out with PhyML (1000 bootstrap replicates), implemented in Geneious v7.1.7. The JTT substitution model (Jones et al., 1992) was used for studying the evolution of a large number of amino acid sequences. Amino-terminal signal sequences were predicted by PRED-TAT (http://www. compgen.org/tools/PRED-TAT) and TOPCONS (http://topcons. cbr.su.se/). Transmembrane regions and topology were predicted by TMHMM (http://www.cbs.dtu.dk/services/TMHMM/), and TOPCONS.

\section{Bacterial Strains and Media}

Strains used in this study are listed in Table S1. E. coli was grown in LB (MP Biomedicals) at $37^{\circ} \mathrm{C}$, whereas Pseudomonas strains were grown with shaking at $200 \mathrm{rpm}$ in Trypticase Soy Broth (TSB, BD Biosciences) and Casamino Acids Medium (CAA, BD Biosciences) at $30^{\circ} \mathrm{C}$, except for $P$. aeruginosa that was grown at $37^{\circ} \mathrm{C}$. Growth media were supplemented with agar (1.5\%, Invitrogen), filter-sterilized isopropyl- $\beta$ D-thiogalactopyranoside (IPTG, $20 \mu \mathrm{g} / \mathrm{ml}$, ForMedium), kanamycin $(50 \mu \mathrm{g} / \mathrm{ml}$, Sigma-Aldrich), or tetracycline (15-150 $\mu \mathrm{g} / \mathrm{ml}$, Sigma-Aldrich) when required. Strains were kept on plate at $4^{\circ} \mathrm{C}$, or at $-80^{\circ} \mathrm{C}$ in glycerol $(25 \% \mathrm{v} / \mathrm{v}$, Sigma-Aldrich).

\section{DNA Methods and Construction of Plasmids}

Genomic DNA was collected with the Puregene Yeast/Bact. Kit B (Qiagen). Synthetic genes and primers were obtained from IDT DNA. Genes encoding bacteriocins (ERS445055_00256 from P. aeruginosa NCTC10332, PFLQ8_1129 from Pseudomonas fluorescens Q8r1-96 (Landa et al., 2003) and PSPTO_0572 from Pseudomonas syringae pv. tomato DC3000) and putative immunity proteins, encoded downstream, were amplified by polymerase chain reaction (PCR) with Q5 polymerase (New England Biolabs), with a T100 ${ }^{\mathrm{TM}}$ Thermal cycler (Bio-Rad). Q5 polymerase was used according to the supplier's specifications. All primers are listed in Table S2. PCR fragments were purified with the Genelute PCR clean-up kit (Sigma-Aldrich), and double digested with $\mathrm{NcoI} / \mathrm{XhoI}\left(1 \mathrm{~h}\right.$ at $37^{\circ} \mathrm{C}$, New England Biolabs) in the case of the bacteriocin genes, and with PstI/XbaI $(1 \mathrm{~h}$ at $37^{\circ} \mathrm{C}$, New England Biolabs) in the case of the putative immunity genes. The immunity gene amplicon of $P$. aeruginosa NCTC10332 was digested with PstI/EcoRI ( $1 \mathrm{~h}$ at $37^{\circ} \mathrm{C}$, New 
England Biolabs). Purified bacteriocin genes were ligated with T4 DNA ligase $\left(1 \mathrm{~h}\right.$ at $37^{\circ} \mathrm{C}$, Invitrogen) in pET28a $(+)$ and putative immunity genes in shuttle vector pJB3Tc20. Ligation products were transformed to $E$. coli $\mathrm{DH} 5 \alpha$ via heat shock. Standard methods were used for the preparation of competent E. coli cells and heat shock transformation of E. coli (Green and Sambrook, 2012). Transformants were initially verified for the presence of insert by PCR with Taq polymerase (New England Biolabs), using conditions as specified by the supplier. Plasmids were subsequently harvested with the Genelute HP plasmid miniprep kit (Sigma-Aldrich) and sequence confirmed for the presence of correct insert (GATC Biotech, Constance, Germany). Cloned immunity genes encompassed a 19-bp upstream region containing the predicted ribosome binding sites. Resulting plasmids are summarized in Table S1. The pET28a constructs were transformed to E. coli BL21/DE3 via heat shock, and pJB3Tc20 constructs electroporated to PseuM-susceptible Pseudomonas strains, and selected on the proper medium. Immunity genes encoding a mutation in a conserved aspartate residue were constructed via splicing by overlap extension, using pCMPG6251 (encoding the putative immunity complement of PseuM $\mathrm{DC}_{\text {2000), pCMPG6252 (complement of PseuM }}$ NCTC10332), and pCMPG6269 (complement of PseuM $\mathrm{Q}_{\mathrm{Q} 81-96}$ ) as a template.

\section{Expression and Purification of Recombinant Bacteriocins}

Recombinant carboxy-terminally His-tagged bacteriocins were generated in E. coli BL21(DE3) carrying pCMPG6248 (encoding PseuM from P. syringae DC3000), pCMPG6250 (encoding PseuM from $P$. aeruginosa NCTC10332) or pCMPG6271 (encoding PseuM from $P$. fluorescens Q8r1-96). Five milliliters of overnight cultures were transferred to $500 \mathrm{ml} \mathrm{LB}$ Erlenmeyer flasks and incubated at $37^{\circ} \mathrm{C}$ until $\mathrm{OD}_{600}$ reached 0.7. After, cultures were cooled and supplemented with IPTG (1 mM final concentration) and incubated at $20^{\circ} \mathrm{C}$ for $16 \mathrm{~h}$. Next day, cells were harvested via centrifugation (20 min, $5000 \mathrm{~g}$; Beckman $\mathrm{X}-15 \mathrm{R})$ and frozen overnight $\left(-20^{\circ} \mathrm{C}\right)$. Subsequently, the cell pellets were thawed, resuspended in lysis buffer $(5 \mathrm{ml} / \mathrm{g}$ cell pellet; $300 \mathrm{mM} \mathrm{NaCl}, 50 \mathrm{mM} \mathrm{NaH} \mathrm{PO}_{4}, 10 \mathrm{mM}$ imidazole, $\mathrm{pH}$ 8.0) and sonicated (amplitude 20\%, 10 cycles of $30 \mathrm{~s}$ on/off; Branson Digital Sonifier). Samples were treated with nuclease $\left(0.01 \mathrm{U} / \mu \mathrm{l}, 37^{\circ} \mathrm{C}, 1 \mathrm{~h}\right.$; Invitrogen), remaining debris and insoluble proteins removed via centrifugation $(30 \mathrm{~min}$, $10000 \mathrm{~g})$, and supernatants filtered $(0.20 \mu \mathrm{m}$, Sarstedt). Soluble fractions containing the recombinant proteins were loaded on a 5-ml HisTrap HP column (GE Healthcare) and purified by nickel affinity chromatography with an Äkta Purifier (GE Healthcare). Matrix-bound proteins were eluted with a linear gradient of imidazole $(10-500 \mathrm{mM})$ in lysis buffer. Fractions eluted at high imidazole concentrations were validated for the presence of recombinant protein, pooled and dialyzed to Tris buffer $(50 \mathrm{mM}, \mathrm{NaCl} 200 \mathrm{mM}, \mathrm{pH}$ 7.5). Concentration of purified PseuMs was determined with a Genesys 10S UV-Vis Spectrophotometer (Thermo Scientific). Calculated extinction coefficients were $30035 \mathrm{~mol} / \mathrm{L}^{-1} \mathrm{~cm}^{-1}, 73340 \mathrm{~mol} / \mathrm{L}^{-1} \mathrm{~cm}^{-1}$, and $32890 \mathrm{~mol} / \mathrm{L}^{-1} \mathrm{~cm}^{-1}$ for the His-tagged PseuM bacteriocins from strains DC3000, NCTC10332, and Q8r1-96, respectively.

\section{Bacteriocin Assay}

Bacteriocin activity was determined via spot assay. Filtersterilized 20- $\mu$ l volumes of purified recombinant proteins $(1 \mathrm{mg} / \mathrm{ml})$ were spotted onto bacterial cell lawns. After, samples were air-dried and incubated overnight. Dialysis buffer was used as a negative control. Following day, petri dishes were scored for zones lacking bacterial growth (halos).

\section{Nucleotide Accession Number}

GenBank accession number of the nucleotide sequence of the pseuM-pmiA pair from $P$. putida RW10S2 (Rokni-Zadeh et al., 2012) is KX086738.

\section{RESULTS}

\section{In silico Search for Candidate Genes Providing Immunity to Pseudomonas Colicin M-like Bacteriocins}

Based on the genetic architecture of modular bacteriocins in Gram-negatives, it is anticipated that bacteriocin immunity genes are likely to be found in proximity of their corresponding toxin genes. By scrutiny of their genomic contexts we observed that the characterized Pseudomonas colicin M-like bacteriocin genes, as well as several other predicted PseuM-encoding genes (Figure S1A), are consistently followed on the same DNA strand-at variable distances but within $<200$ nucleotides-by an open reading frame, but infrequently annotated as a coding region (Table S3). Typically, G+C content of these regions $(\sim 1.8 \mathrm{~kb})$ is significantly lower (41-52\%) than the Pseudomonas genome averages ( $P$. aeruginosa: 66.2\%, 1647 genomes; $P$. fluorescens: 60.2\%, 92 genomes; $P$. syringae: 58.7\%, 153 genomes). None of the deduced protein sequences contains the YebF domain signature (Pfam PF13995) as found in Cmi and the putative pectocin $\mathrm{M}$ immunity proteins.

In 14 Pseudomonas strains, mostly $P$. syringae pathovars, the encoded proteins (encompassing eight unique but very similar sequences of $\sim 100$ AAs) show only borderline homology with the burkhocin-associated $\mathrm{BmiB}$ immunity proteins (12-24\% pairwise AA identity). However, these pseudomonad proteins, designated PmiBs, share with BmiBs two perfectly conserved cysteines (Figure $\mathrm{S} 2$ ). The $\mathrm{PmiB}$ and $\mathrm{BmiB}$ proteins are predicted to be translocated to the periplasm, albeit this appears to be achieved in different ways: instead of the BmiB amino-terminal membrane-anchoring segment or Sec-dependent cleavable signal sequence, a cleavable lipoprotein signal sequence typifies PmiB. This common feature is reflected in the phylogeny of ColM domains that reveals a well-separated clade harboring both the burkhocins and this small subset of PseuM proteins (Figure S1B).

The majority of PseuM-derived ColM domains constitutes a separate clade of much more diversified sequences that are evolutionarily related to the corresponding domains in colicin $\mathrm{M}$ and colicin $\mathrm{M}$ domain-containing pectocins (Figure 1A, Figure S1B). In this second subset of PseuM-bacteriocinogenic strains the bacteriocin gene is linked with a gene encoding 
a protein unrelated to $\mathrm{PmiB}(\sim 137$ AAs; Figure S3). This protein family, designated PmiA, features four transmembrane helices, of which the first is predicted to represent a candidate Sec- or Tat-dependent cleavable signal sequence (Figure 2). The inferred topology, with two moieties facing the periplasm and two stretches (including the carboxy-terminus) residing in the cytoplasm, is reminiscent of the one adopted by BmiA proteins, albeit the latter lack an equivalent secretory signal sequence (Ghequire and De Mot, 2015b). No sequence homology can be detected between BmiAs and PmiAs however. Notably, four phytopathogenic strains of the $P$. syringae group each carry two unlinked PseuM-encoding paralogues, one from each PseuM clade and clustered with, respectively, a $p m i A$ and $p m i B$ gene. The low level of sequence identity between these bacteriocins ( $24 \%)$ combined with the different nature of the respective candidate immunity proteins argues against a common ancestry and favors their independent acquisition.

In different strains, the pseuM-pmiA gene pair has been recruited to diverse genomic locations. Several of these regions correspond to mobile elements. In P. aeruginosa, the gene couple generally occurs on ExoU island A, as has previously been noted for the pseuM of P. aeruginosa JJ692 (Barreteau et al., 2009).
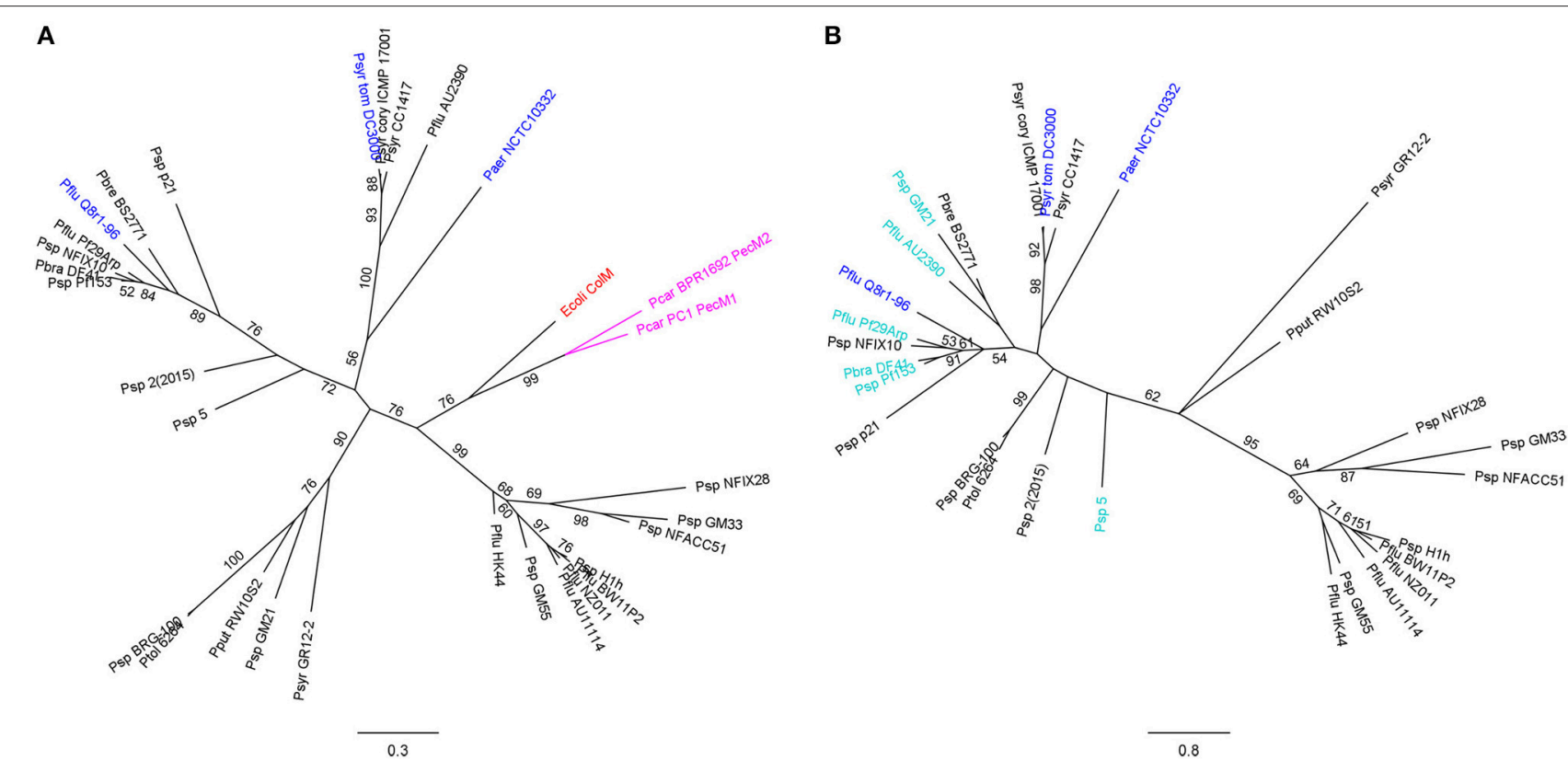

FIGURE 1 | Maximum likelihood phylogenetic trees of ColM domains from pmiA-associated PseuMs and from related $\gamma$-proteobacterial bacteriocins (A), and of associated Pseudomonas PmiA immunity proteins (B). Characterized PseuM bacteriocins and cognate PmiAs are colored blue, colicin M (CoIM) from E. coli is shown in red, and colicin M domain-containing pectocins (PecM1 and PecM2) in pink. PmiAs that were studied for promiscuity are shown in teal. The scale bars represent 0.3 (A) and 0.8 (B) substitutions per site. Bootstrap values (percentages of 1000 replicates) higher than 50 are shown at the branches. (A) For highly homologous colicin M domains (>95\% pairwise AA identity), only one representative was included for phylogenetic tree construction. Species abbreviations: Ecoli, Escherichia coli; Paer, Pseudomonas aeruginosa; Pbra, Pseudomonas brassicacearum; Pbre, Pseudomonas brenneri; Pcar, Pectobacterium carotovorum; Pflu, Pseudomonas fluorescens; Pput, Pseudomonas putida; Psp, Pseudomonas sp.; Psyr, Pseudomonas syringae; Psyr cory, P. syringae pv. coryli; Psyr tom, P. syringae pv. tomato; Ptol, Pseudomonas tolaasii.

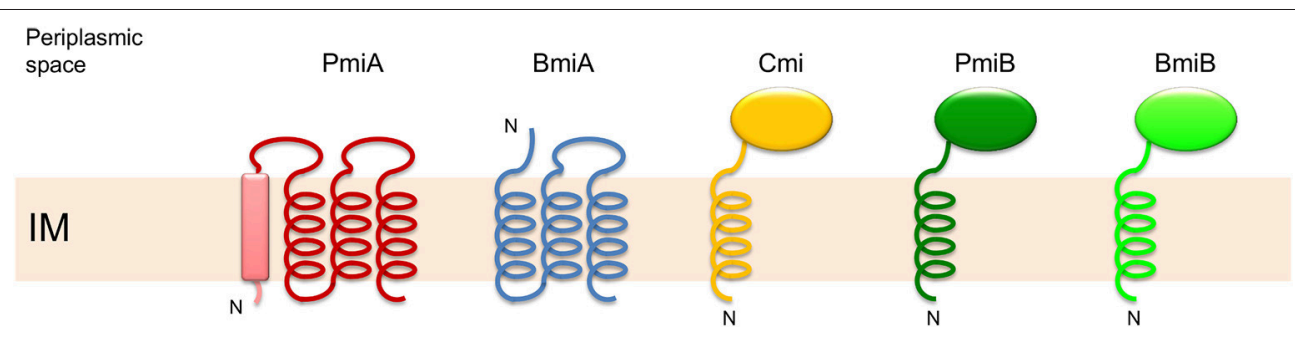

FIGURE 2 | Membrane topology model of integral membrane proteins PmiA and BmiA, and membrane-anchored proteins Cmi, PmiB, and BmiB, providing immunity to the activity of the ColM domain. PmiA from Pseudomonas has four predicted transmembrane helices, the first of which may represent a Sec- or Tat-dependent signal sequence (box). BmiA from Burkholderia carries three transmembrane helices. Cmi has a periplasmic YebF domain and is anchored in the inner membrane (IM) via an amino-terminal helix. PmiB and BmiB are equally anchored in the IM, and carry homologous periplasmic domains. "N" depicts the amino-terminus. 
In some strains from the $P$. syringae group, such as isolates 642 and LMG 2367, pseuM-pmiA combinations appear as a cargo gene couple in a $\operatorname{trpE} / \operatorname{tr} p G$-integrated Rp4 tailocin cluster (Hockett et al., 2015). In other $P$. syringae pathovar strains, such as DC3000 and ICMP 3923, the cargo is equally part of a Rp4-type sequence, although incomplete and apparently linked with diverged sequences. In some $P$. fluorescens group strains, such as Pseudomonas brassicacearum NFM421 and 51MFVCI2.1, and $P$. fluorescens Q8r1-96, the gene pair has been recruited by a Rp4 tailocin cluster as well, sandwiched between mutS and cinA (Ghequire et al., 2015; Hockett et al., 2015). For other strains, such as P. veronii R4, Pseudomonas sp. BRG-100 and Pseudomonas tolaasii 6264, regions flanking the pseuM-pmiA couples correspond to an unassigned prophage. The presence of bacteriocin cargo genes on mobile elements has previously been noted for lectin-like bacteriocins embedded in Pseudomonas Rp2 tailocin clusters (Ghequire et al., 2015).

Some Pseudomonas strains carry a pmiA gene that is not linked to a cognate pseuM gene. The presence of pseuM remnant sequences upstream of such a pmiA orphan indicates that these strains may represent so-called cheaters that have lost the capacity of bacteriocin production but retain the associated immune function (Figure 3). For instance, in the type strain Pseudomonas lundensis (DSM 6252; De Jonghe et al., 2011) a frameshift impairs functionality of a pseuM gene that has remained intact in Pseudomonas sp. AU9518. From the equivalent genomic region of type strain Pseudomonas weihenstephanensis (DSM 291166; von Neubeck et al., 2016) and some related strains (TAD18; TAA207 and DSM 28140, not included in Figure 3), most of the $3^{\prime}$ region of a pseuM gene has been deleted, while their pmiA genes are well-conserved ( $>92 \%$ AA identity). No obvious pseuM sequences remain adjacent to the pmiA gene of Arabidopsis isolate Pseudomonas sp. Leaf48 (Bai et al., 2015), that is flanked by prophage genes.

\section{PmiA Proteins are Cognate PseuM Immunity Partners}

Previously described PseuM bacteriocins from $P$. aeruginosa NCTC10332 (PaeM), P. fluorescens Q8r1-96 (PflM), and P. syringae pv. tomato DC3000 (PsyM), each with a downstream pmiA gene (as identified by in silico analysis described in Section In silico Search for Candidate Genes Providing Immunity to Pseudomonas Colicin M-like Bacteriocins), were recombinantly expressed in E. coli and the His-tagged proteins purified by Ni-NTA affinity chromatography. Strain NCTC10332 encodes a PseuM bacteriocin that shares 90\% AA identity with PaeM from P. aeruginosa JJ692 (Barreteau et al., 2009). Antibacterial activity of the recombinant proteins was challenged via spot-on-lawn assay against a panel of Pseudomonas strains, and strains with a clear halo susceptibility phenotype were selected for further

\section{A PspAu9518 \\ Plun DSM 6252 \\ Psp TAD18 \\ Pwei DSM 29166 \\ B Psp GM55 \\ Pflu S613 \\ C Psp NFACC04-2 \\ Psp NFACC37-1 \\ D Psp NFACC51 \\ Psp NFACC07-1 \\ E Pfre ERGS4:02 \\ F Psp Leaf48}
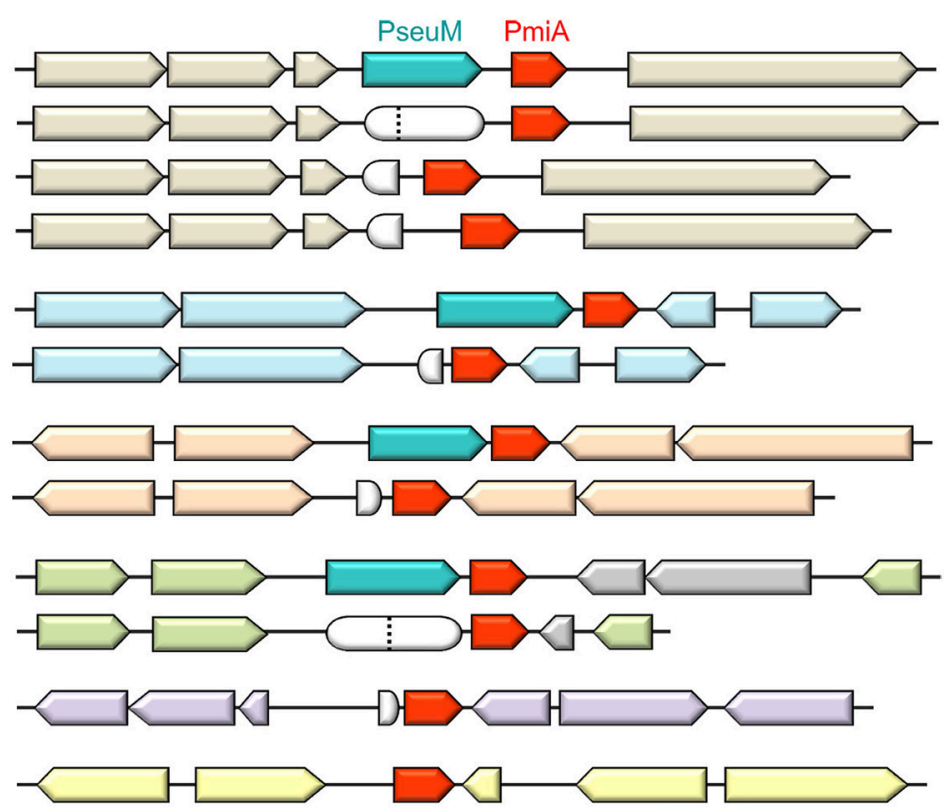

500 bp

FIGURE 3 | Genomic context of orphan pmiA genes in pseudomonads. Syntenic regions carrying a pmiA homolog associated with a full-length PseuM-encoding gene are shown for Pseudomonas sp. strains AU9518 (A), GM55 (B), NFACC04-2 (C), and NFACC51 (D). Synteny between these predicted bacteriocin producers and phylogenetically related cheaters lacking a (functional) bacteriocin gene is highlighted by upstream and downstream ORFs (arrows) shown in the same color. The gray-colored ORFs (D) reflect a local lack of synteny. Remnants of the respective pseuM genes are represented by white-colored rounded shapes corresponding to a frameshifted pseuM (position marked by a dotted vertical line) or a truncated residual $\mathrm{N}$ - or C-terminal fragment. For Pseudomonas strains ERGS4:02 (E) and Leaf48 (F), no strain with a closely related pmiA homolog and syntenic flanking region could be identified. Species abbreviations: Pfre, Pseudomonas frederikbergensis; Plun, Pseudomonas lundensis; Pwei, Pseudomonas weihenstephanensis. Other abbreviations are as in Figure $\mathbf{1 .}$ 
experiments. Such indicator strains identified for PaeM, PflM, and PsyM were P. aeruginosa CPHL12447, P. fluorescens F113, and $P$. syringae pv. lachrymans LMG 5456 (Grinter et al., 2012b), respectively.

Next, the putative immunity genes from strains NCTC10332, Q8r1-96 and DC3000 were cloned in shuttle vector pJB3Tc20, and introduced in the corresponding PseuM-susceptible strains. Transformants were tested for altered PseuM sensitivity, using strains carrying empty vectors as negative controls (Table 1). When equipped with the cognate $p m i A$, transformants became fully insensitive to the respective bacteriocin (tested at $1 \mathrm{mg} / \mathrm{ml}$ by spot assay). When indicator strains were provided with either of the other two immunity genes, no diminished PseuM inhibition was observed. Together this indicates that PmiAs are cognate immunity partners of the bacteriocins they are associated with. Purified membrane fragments with the gene product of $p_{m i A_{D C 3000}}$ were analyzed via Maldi-MSMS (Poetsch et al., 2008), but no peptide fragments assignable to the PmiA of interest could be retrieved (data not shown).

Since colicin $\mathrm{M}$ and colicin M-like bacteriocins domains exert their action in the periplasm, it is plausible that (at least part of) the periplasm-exposed moieties of PmiA proteins participate in the immunity function, directly or indirectly impeding the catalytic function of the ColM domain. Conserved residues in the immunity module may be critical in providing such property. In the mature PmiA proteins, a short well-conserved stretch with consensus motif $\mathrm{D}[\mathrm{T} / \mathrm{S}] \mathrm{XGXP}$ precedes the second predicted transmembrane segment (Figure 4, Figure S3). No obvious sequence conservation among PmiA proteins can be detected for the shorter second periplasm-exposed loop. To further scrutinize the possible role of the first periplasmic stretch, the conserved Asp residue was mutated to Ala in the PmiAs of strains NCTC10332, Q8r1-96 and DC3000. Upon introduction of the PmiA variants in the respective indicator strains, the immunity phenotype to the respective PseuMs was evaluated. Halos were absent for all three indicator strains after bacteriocin spotting, showing the same phenotype as caused by the native immunity gene products (Table 1). This suggests that the conserved Asp residue is not instrumental to PmiA's immunity function.

\section{Immune Promiscuity among Sequence-Diverged PmiAs}

Noteworthy, sequence divergence of the PseuM-PmiA toxinimmunity pairs seems to be most pronounced among strains belonging to the $P$. fluorescens group. In contrast, for $P$. syringae

TABLE 1 | Heterologous expression of pmiA genes in PseuM-susceptible strains.

\begin{tabular}{|c|c|c|c|c|c|}
\hline \multirow[t]{2}{*}{ Indicator strain } & \multicolumn{2}{|c|}{ PmiA immunity protein } & \multicolumn{3}{|c|}{ PseuM bacteriocin } \\
\hline & Species & Gene product & $\begin{array}{c}\text { PaeM } \\
\text { P. aeruginosa } \\
\text { NCTC10332 }\end{array}$ & $\begin{array}{c}\text { PfIM } \\
\text { P. fluorescens } \\
\text { Q8r1-96 }\end{array}$ & $\begin{array}{c}\text { PsyM } \\
\text { P. syringae pv. tomato } \\
\text { DC3000 }\end{array}$ \\
\hline \multirow[t]{5}{*}{ P. aeruginosa CPHL12447 } & $P$. aeruginosa & PmiAnCTC10332 $_{1}$ & - & & \\
\hline & & $\mathrm{Pmi}^{\star}{ }^{\star}$ NCTC10332 & - & & \\
\hline & P. fluorescens & $P_{m i} A_{Q 8 r 1-96}$ & + & & \\
\hline & P. syringae pv. tomato & PmiADC3000 & + & & \\
\hline & NA & Control & + & & \\
\hline \multirow[t]{11}{*}{ P. fluorescens F113 } & $P$. aeruginosa & Pmi $_{\text {NCTC10332 }}$ & & + & \\
\hline & P. brassicacearum & PmiAdF41 & & - & \\
\hline & P. fluorescens & $P_{m i} A_{Q 8 r 1-96}$ & & - & \\
\hline & & $\mathrm{PmiA}^{*} \mathrm{Q} 8 \mathrm{r} 1-96$ & & - & \\
\hline & & $P_{m i} A_{A \cup 2390}$ & & + & \\
\hline & & PmiApf29Arp & & - & \\
\hline & P. syringae pv. syringae & $\operatorname{Pmi}_{\mathrm{DC} 3000}$ & & + & \\
\hline & Pseudomonas sp. & $\mathrm{PmiA}_{5}$ & & $\mathrm{~T}$ & \\
\hline & & $P_{m i} A_{G M 21}$ & & + & \\
\hline & & PmiApf153 & & - & \\
\hline & NA & Control & & + & \\
\hline \multirow[t]{4}{*}{ P. syringae LMG 5456} & $P$. aeruginosa & $\operatorname{Pmi}_{\text {NCTC10332 }}$ & & & + \\
\hline & P. syringae pv. tomato & $\mathrm{Pmi}_{\mathrm{DC} 3000}$ & & & - \\
\hline & & $\mathrm{PmiA}^{\star}$ DC3000 & & & - \\
\hline & NA & Control & & & + \\
\hline
\end{tabular}

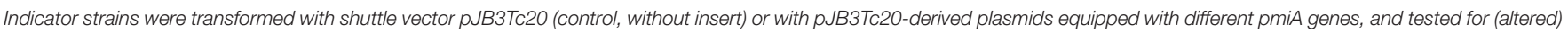

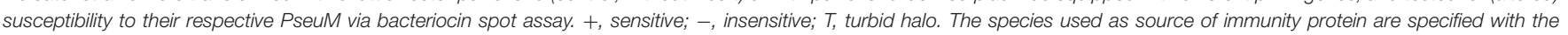

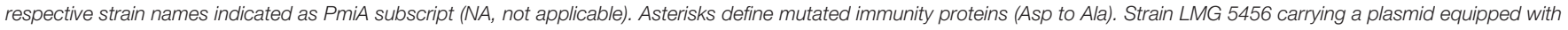
pmiA $_{Q 8 \mathrm{r} 1-96}$ could not be obtained. 


\begin{tabular}{|c|c|}
\hline $\begin{array}{l}\text { Psp BRG-100 } \\
\text { Ptol 6264 } \\
\text { Pput RW10S2 } \\
\text { Psp GM21 } \\
\text { Psyr GR12-2 } \\
\text { Psp GM33 } \\
\text { Psp NFIX28 } \\
\text { Psp NFACC51 } \\
\text { Psp H1h } \\
\text { Pflu BW11P2 } \\
\text { Pflu NZ011 } \\
\text { Pflu AU11114 } \\
\text { Psp GM55 } \\
\text { Pflu HK44 } \\
\text { Psp 2(2015) } \\
\text { Psp 5 } \\
\text { Psp Pf153 } \\
\text { Pbra DF41 } \\
\text { Psp NFIX10 } \\
\text { Pflu Pf29Arp } \\
\text { Pflu Q8r1-96 } \\
\text { Pbre BS2771 } \\
\text { Psp p21 } \\
\text { Pflu AU2390 } \\
\text { Paer NCTC10332 } \\
\text { Psyr CC1417 } \\
\text { Psyr cory ICMP 17001 } \\
\text { Psyr tom DC3000 }\end{array}$ & 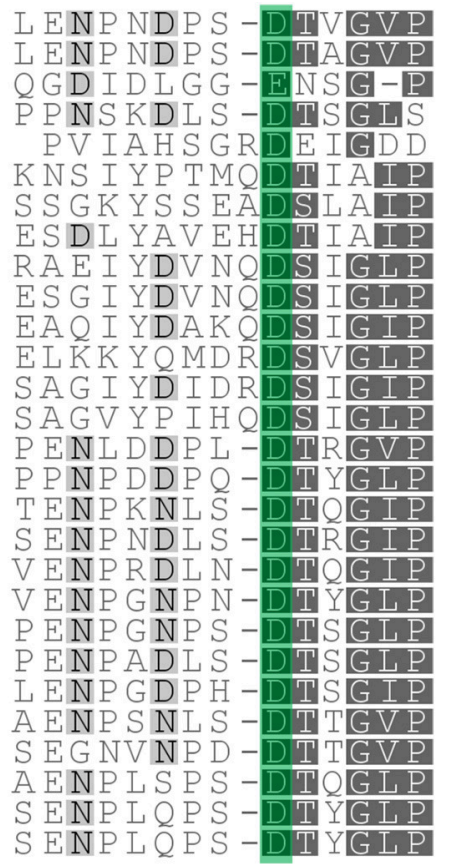 \\
\hline \multicolumn{2}{|c|}{$\begin{array}{l}\text { FIGURE } 4 \text { | Multiple sequence alignment of the semi-conserved stretch } \\
\text { in PmiA proteins, predicted to be oriented toward the periplasmic } \\
\text { space. Pseudomonas species abbreviations are as in Figure 1. Gray shading } \\
\text { reflects the degree of conservation. The conserved Asp residue that was } \\
\text { mutated is boxed in green. }\end{array}$} \\
\hline
\end{tabular}

pathovar isolates, high conservation of the ColM domain (at least 94\% pairwise AA identity; Figures S1A,B) is reflected in wellconserved immunity proteins (at least $84 \%$ pairwise AA identity). Previously, it was demonstrated that immunity proteins sharing high homology may provide pyocin-silencing functionality of another partner (Dingemans et al., 2016).

To examine to what extent sequence divergence limits the immune function, PmiA homologs from the cluster with P. fluorescens Q8r1-96 were selected (P. brassicacearum DF41, P. fluorescens Pf29Arp, and Pseudomonas sp. Pf153), as well as some more distant PmiAs (Pseudomonas sp. strains 5 and GM21, P. fluorescens AU2390; Figure 1B). The PmiAs from the Q8r1-96 cluster share 36-40\% AA identity with PmiA $\mathrm{Q}_{\mathrm{Q} 8 \mathrm{r}-96}$. This level of sequence conservation stems mainly from the periplasm-exposed regions as well as the transmembrane helices, whereas the amino-terminal signal sequence/transmembrane helix and the cytoplasm-exposed stretches exhibit extensive sequence divergence. By comparison, the ColM domains of the PseuMs of strains DF41, Pf29Arp and Pf153, display considerably higher sequence conservation ( $\sim 69 \%$ AA identity) with PflM. Pairwise identity with the more distant PmiAs ranges from 18 to $31 \%$, corresponding with more diversified ColM domains (35-46\% AA identity with PflM).

These six pmiA genes were cloned in pJB3Tc20 and introduced in P. fluorescens F113, and tested for their capacity to protect from PflM activity, using empty vector and the native $p m i A_{\mathrm{Q} 8 \mathrm{r} 196}$ immunity gene as controls for susceptibility and immunity, respectively (Table 1 ). Despite only moderate pairwise identities to PmiA ${ }_{\mathrm{Q} 8 \mathrm{r1}-96}, \mathrm{PmiA}_{\mathrm{DF} 41}, \mathrm{PmiA}_{\mathrm{Pf} 153}$, and PmiA $\mathrm{Pf}_{29 A r p}$ provided full cross-immunity to PflM. The more distantly related PmiAs from strains AU2390 and GM21 (with 30.9 and 23.4\% AA identity, respectively) could not immunize cells against the bacteriocin, resulting in a similar phenotype as the PmiAs from $P$. aeruginosa NCTC10332 and $P$. syringae DC3000, and the control. Despite barely showing homology with PmiA $\mathrm{Q} 8 \mathrm{r} 1-96$ (18.4\% AA identity), PmiA from Pseudomonas sp. 5 conferred an intermediate immunity phenotype (turbid halo).

\section{DISCUSSION}

In this study we demonstrated that cognate immunity to a large subset of ColM domain-containing Pseudomonas bacteriocins is provoked by the poorly conserved transmembrane protein PmiA, unrelated in sequence and topology to the Cmi protein providing immunity to colicin $\mathrm{M}$ in $E$. coli. The pmiA gene, consistently located downstream of pseuM on the same strand, is rarely annotated (Table S3). Previously, immunity to ColM domains in Burkholderia burkhocins was equally associated with a transmembrane protein (BmiA; Ghequire and De Mot, 2015b). However, since ColM domains from $b m i A$ - and pmiA-associated bacteriocins constitute phylogenetically distant clades, the immunity mechanism from these integral membrane proteins may be different. Further support for the existence of such evolutionarily distinct lipid II-targeting bacteriocin subsets is provided by the observation that a minor group of pseudomonad genes shares a similar immunity gene, as well as a similar ColM-domain-encoding gene, with Burkholderia. The gene organization of different ColM domain-hosting bacteriocins and their (putative) immunity genes is summarized in Figure 5.

A conserved Asp residue located in a semi-conserved periplasm-exposed stretch proved not pivotal for the immunity phenotype of PmiA. Possibly, it is required for structural integrity or stability of the immunity protein, and structural analysis can give more insight in this issue. Since the periplasmexposed moieties of PmiA likely contribute to immunity, it was investigated whether cross-immunity between proteins with different extent of sequence conservation in those regions, may occur. Since this was found to be the case, even between PmiAs sharing $<40 \%$ pairwise amino acid identity, it will be of future interest to determine which residues or structural elements actually contribute to the immunity phenotype. This will render a first indication on how and where the immunity mechanism to this toxin module may be provoked. Previously, attempts to co-crystallize colicin $\mathrm{M}$ and $\mathrm{Cmi}$ to enlighten how Cmi neutralizes ColM-mediated toxicity proved unsuccessful (Usón et al., 2012).

From an evolutionary point of view, promiscuous protection by immunity genes sharing low homology may have far-reaching consequences toward competitive advantage for producer strains. It may explain why genome analysis in pseudomonads indicated that PseuMs are rather rare, as compared to DNase and RNase bacteriocins (Ghequire and De Mot, 2014). In contrast, 


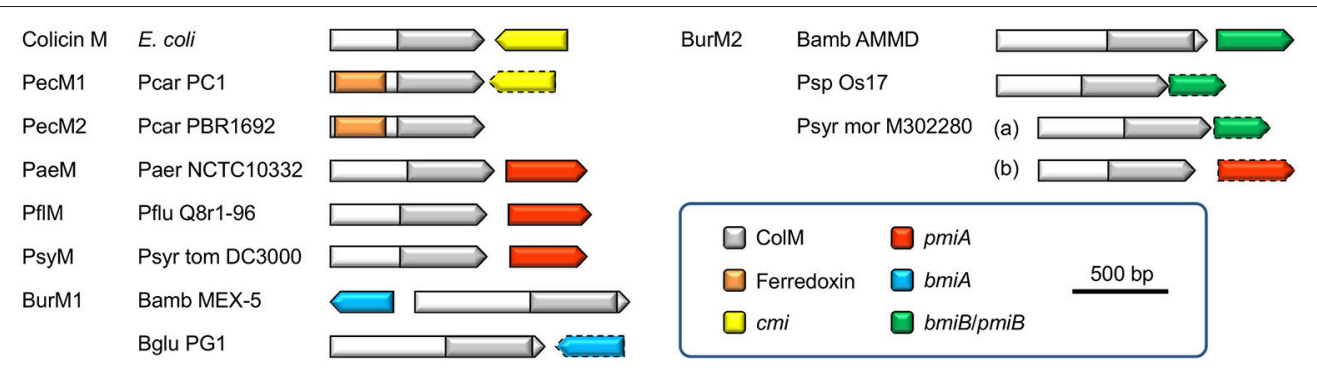

FIGURE 5 | Schematic gene organizations of CoIM domain-containing bacteriocins and (putative) immunity genes (if present). The arrows correspond with the gene orientations and the color legend describes the indicated domains and type of immunity gene. Predicted immunity genes, based on homology with characterized immunity factors, are delineated by a dashed line. Species abbreviations are as in Figure 1. Bamb, Burkholderia ambifaria; Bglu, Burkholderia glumae.

immunity to the latter bacteriocins is provided by immunity proteins forming very specifically high-affinity bacteriocinimmunity complexes, stabilized by conserved hydrogen bonds and hydrophobic interactions ( $\mathrm{Li}$ et al., 2004; Levin et al., 2009; Meenan et al., 2010; Joshi et al., 2015; Kleanthous et al., 2016). PseuM bacteriocin production may therefore provide limited benefit in most environments, and hence result in lower selection pressure to maintain these bacteriocins in genomes. In addition to this, genome mining also indicated that orphan pmiA-like genes occasionally occur in Pseudomonas genomes, although it remains to be investigated whether these enable cheating. A similar observation was made for bmiA genes in Burkholderia (Ghequire and De Mot, 2015b) and S-type pyocin immunity genes (Ghoul et al., 2015).

\section{AUTHOR CONTRIBUTIONS}

MG, RD conceived and designed the experiments; MG and LK performed the experiments; MG, LK, and RD analyzed the data;

\section{REFERENCES}

Bai, Y., Müller, D. B., Srinivas, G., Garrido-Oter, R., Potthoff, E., Rott, M., et al. (2015). Functional overlap of the Arabidopsis leaf and root microbiota. Nature 528, 364-369. doi: 10.1038/nature16192

Barreteau, H., Bouhss, A., Fourgeaud, M., Mainardi, J. L., Touzé, T., Gérard, F., et al. (2009). Human- and plant-pathogenic Pseudomonas species produce bacteriocins exhibiting colicin M-like hydrolase activity towards peptidoglycan precursors. J. Bacteriol. 191, 3657-3664. doi: 10.1128/JB.01824-08

Barreteau, H., Tiouajni, M., Graille, M., Josseaume, N., Bouhss, A., Patin, D., et al. (2012). Functional and structural characterization of PaeM, a colicin M-like bacteriocin produced by Pseudomonas aeruginosa. J. Biol. Chem. 287, 37395-37405. doi: 10.1074/jbc.M112.406439

Cascales, E., Buchanan, S. K., Duché, D., Kleanthous, C., Lloubès, R., Postle, K., et al. (2007). Colicin biology. Microbiol. Mol. Biol. Rev. 71, 158-229. doi: 10.1128/MMBR.00036-06

De Jonghe, V., Coorevits, A., Van Hoorde, K., Messens, W., Van Landschoot, A., De Vos, P., et al. (2011). Influence of storage conditions on the growth of Pseudomonas species in refrigerated raw milk. Appl. Environ. Microbiol. 77, 460-470. doi: 10.1128/AEM.00521-10

Dingemans, J., Ghequire, M. G., Craggs, M., De Mot, R., and Cornelis, P. (2016). Identification and functional analysis of a bacteriocin, pyocin S6, with
MG and RD wrote the paper; all authors approved the final version of the manuscript.

\section{FUNDING}

MG is the recipient of a postdoctoral fellowship from FWOVlaanderen $(12 \mathrm{M} 4615 \mathrm{~N})$.

\section{ACKNOWLEDGMENTS}

The author wish to thank Dr. Linda Thomashow (Washington State University) for kindly providing P. fluorescens Q8r1-96. The authors wish to thank Prof. Bart Devreese (Ghent University) for MS analysis and suggestions for improving this manuscript.

\section{SUPPLEMENTARY MATERIAL}

The Supplementary Material for this article can be found online at: http://journal.frontiersin.org/article/10.3389/fmicb. 2017.00093/full\#supplementary-material ribonuclease activity from a Pseudomonas aeruginosa cystic fibrosis clinical isolate. Microbiologyopen 5, 413-423. doi: 10.1002/mbo3.339

Gérard, F., Brooks, M. A., Barreteau, H., Touzé, T., Graille, M., Bouhss, A., et al. (2011). X-ray structure and site-directed mutagenesis analysis of the Escherichia coli colicin M immunity protein. J. Bacteriol. 193, 205-214. doi: 10.1128/JB.01119-10

Gerstmans, H., Rodríguez-Rubio, L., Lavigne, R., and Briers, Y. (2016). From endolysins to Artilysin $(\mathrm{s}$ : novel enzyme-based approaches to kill drugresistant bacteria. Biochem. Soc. Trans. 44, 123-128. doi: 10.1042/BST20150192

Ghequire, M. G., and De Mot, R. (2014). Ribosomally encoded antibacterial proteins and peptides from Pseudomonas. FEMS Microbiol. Rev. 38, 523-568. doi: 10.1111/1574-6976.12079

Ghequire, M. G., and De Mot, R. (2015a). The tailocin tale: peeling off phage tails. Trends Microbiol. 23, 587-590. doi: 10.1016/j.tim.2015.07.011

Ghequire, M. G., and De Mot, R. (2015b). Distinct colicin M-like bacteriocinimmunity pairs in Burkholderia. Sci. Rep. 5:17368. doi: 10.1038/srep17368

Ghequire, M. G., Dillen, Y., Lambrichts, I., Proost, P., Wattiez, R., and De Mot, R. (2015). Different ancestries of R tailocins in rhizospheric Pseudomonas isolates. Genome Biol. Evol. 7, 2810-2828. doi: 10.1093/gbe/evv184

Ghequire, M. G., Dingemans, J., Pirnay, J. P., De Vos, D., Cornelis, P., and De Mot, R. (2014). O serotype-independent susceptibility of Pseudomonas aeruginosa to lectin-like pyocins. Microbiologyopen 3, 875-884. doi: 10.1002/mbo3.210 
Ghequire, M. G., Garcia-Pino, A., Lebbe, E. K., Spaepen, S., Loris, R., and De Mot, R. (2013). Structural determinants for activity and specificity of the bacterial toxin LlpA. PLoS Pathog. 9:e1003199. doi: 10.1371/journal.ppat.1003199

Ghoul, M., West, S. A., Johansen, H. K., Molin, S., Harrison, O. B., Maiden, M. C., et al. (2015). Bacteriocin-mediated competition in cystic fibrosis lung infections. Proc. Biol. Sci. 282, 1814. doi: 10.1098/rspb.2015.0972

Green, M. R., and Sambrook, J. (2012). Molecular Cloning: A Laboratory Manual. New York, NY: Cold Spring Harbor.

Grinter, R., Josts, I., Zeth, K., Roszak, A. W., McCaughey, L. C., Cogdell, R. J., et al. (2014). Structure of the atypical bacteriocin pectocin M2 implies a novel mechanism of protein uptake. Mol. Microbiol. 93, 234-246. doi: $10.1111 / \mathrm{mmi} .12655$

Grinter, R., Milner, J., and Walker, D. (2012a). Ferredoxin containing bacteriocins suggest a novel mechanism of iron uptake in Pectobacterium spp. PLoS ONE 7:e33033. doi: 10.1371/journal.pone.0033033

Grinter, R., Roszak, A. W., Cogdell, R. J., Milner, J. J., and Walker, D. (2012b). The crystal structure of the lipid II-degrading bacteriocin syringacin M suggests unexpected evolutionary relationships between colicin M-like bacteriocins. J. Biol. Chem. 287, 38876-38888. doi: 10.1074/jbc.M112.400150

Gross, P., and Braun, V. (1996). Colicin M is inactivated during import by its immunity protein. Mol. Gen. Genet. 251, 388-396. doi: 10.1007/BF02172531

Hockett, K. L., Renner, T., and Baltrus, D. A. (2015). Independent co-option of a tailed bacteriophage into a killing complex in Pseudomonas. MBio 6:e00452. doi: 10.1128/mBio.00452-15

Holt, K. E., Thieu Nga, T. V., Thanh, D. P., Vinh, H., Kim, D. W., Vu Tra, M. P., et al. (2013). Tracking the establishment of local endemic populations of an emergent enteric pathogen. Proc. Natl. Acad. Sci. U.S.A. 110, 17522-17527. doi: $10.1073 /$ pnas. 1308632110

Jones, D. T., Taylor, W. R., and Thornton, J. M. (1992). The rapid generation of mutation data matrices from protein sequences. Comput. Appl. Biosci. 8, 275-282. doi: 10.1093/bioinformatics/8.3.275

Joshi, A., Grinter, R., Josts, I., Chen, S., Wojdyla, J. A., Lowe, E. D., et al. (2015). Structures of the ultra-high-affinity protein-protein complexes of pyocins S2 and AP41 and their cognate immunity proteins from Pseudomonas aeruginosa. J. Mol. Biol. 427, 2852-2866. doi: 10.1016/j.jmb.2015.07.014

Kleanthous, C., Klein, A., Wojdyla, J., Joshi, A., Josts, I., McCaughey, L. C., et al. (2016). Structural and biophysical analysis of nuclease proteins antibiotics. Biochem. J. 473, 2799-2812. doi: 10.1042/BCJ20160544

Landa, B. B., Mavrodi, D. M., Thomashow, L. S., and Weller, D. M. (2003). Interactions between strains of 2,4-diacetylphloroglucinol-producing Pseudomonas fluorescens in the rhizosphere of wheat. Phytopathology 93, 982-994. doi: 10.1094/PHYTO.2003.93.8.982

Levin, K. B., Dym, O., Albeck, S., Magdassi, S., Keeble, A. H., Kleanthous, C., et al. (2009). Following evolutionary paths to protein-protein interactions with high affinity and selectivity. Nat. Struct. Mol. Biol. 16, 1049-1055. doi: $10.1038 / \mathrm{nsmb} .1670$

Li, W., Keeble, A. H., Giffard, C., James, R., Moore, G. R., and Kleanthous, C. (2004). Highly discriminating protein-protein interaction specificities in the context of a conserved binding energy hotspot. J. Mol. Biol. 337, 743-759. doi: 10.1016/j.jmb.2004.02.005

McCaughey, L. C., Grinter, R., Josts, I., Roszak, A. W., Waløen, K. I., Cogdell, R. J., et al. (2014). Lectin-like bacteriocins from Pseudomonas spp. utilise D-rhamnose containing lipopolysaccharide as a cellular receptor. PLoS Pathog. 10:e1003898. doi: 10.1371/journal.ppat.10 03898

McCaughey, L. C., Josts, I., Grinter, R., White, P., Byron, O., Tucker, N. P., et al. (2016). Discovery, characterisation and in vivo activity of pyocin SD2, a protein antibiotic from Pseudomonas aeruginosa. Biochem. J. 473, 2345-2358. doi: 10.1042/BCJ20160470

Meenan, N. A., Sharma, A., Fleishman, S. J., Macdonald, C. J., Morel, B., Boetzel, R., et al. (2010). The structural and energetic basis for high selectivity in a high-affinity protein-protein interaction. Proc. Natl. Acad. Sci. U.S.A. 107, 10080-10085. doi: 10.1073/pnas.0910756107

Olschläger, T., and Braun, V. (1987). Sequence, expression, and localization of the immunity protein for colicin M. J. Bacteriol. 169, 4765-4769. doi: $10.1128 /$ jb.169.10.4765-4769.1987

Olschläger, T., Schramm, E., and Braun, V. (1984). Cloning and expression of the activity and immunity genes of colicins B and M on ColBM plasmids. Mol. Gen. Genet. 196, 482-487. doi: 10.1007/BF00436196

Olschläger, T., Turba, A., and Braun, V. (1991). Binding of the immunity protein inactivates colicin M. Mol. Microbiol. 5, 1105-1111. doi: 10.1111/j.1365-2958.1991.tb01883.x

Poetsch, A., Schlüsener, D., Florizone, C., Eltis, L., Menzel, C., Rögner, M., et al. (2008). Improved identification of membrane proteins by MALDI-TOF MS/MS using vacuum sublimated matrix spots on an ultraphobic chip surface. J. Biomol. Tech. 19, 129-138.

Rokni-Zadeh, H., Li, W., Sanchez-Rodriguez, A., Sinnaeve, D., Rozenski, J., Martins, J. C., et al. (2012). Genetic and functional characterization of cyclic lipopeptide white-line-inducing principle (WLIP) production by rice rhizosphere isolate Pseudomonas putida RW10S2. Appl. Environ. Microbiol. 78, 4826-4834. doi: 10.1128/AEM.00335-12

Schulz, S., Stephan, A., Hahn, S., Bortesi, L., Jarczowski, F., Bettmann, U., et al. (2015). Broad and efficient control of major foodborne pathogenic strains of Escherichia coli by mixtures of plant-produced colicins. Proc. Natl. Acad. Sci. U.S.A. 112, E5454-E5460. doi: 10.1073/pnas.1513311112

Usón, I., Patzer, S. I., Rodríguez, D. D., Braun, V., and Zeth, K. (2012). The crystal structure of the dimeric colicin $\mathrm{M}$ immunity protein displays a 3D domain swap. J. Struct. Biol. 178, 45-53. doi: 10.1016/j.jsb.2012. 02.004

von Neubeck, M., Huptas, C., Glück, C., Krewinkel, M., Stoeckel, M., Stressler, T., et al. (2016). Pseudomonas helleri sp. nov. and Pseudomonas weihenstephanensis sp. nov., isolated from raw cow's milk. Int. J. Syst. Evol. Microbiol. 66, 1163-1173. doi: 10.1099/ijsem.0.000852

Conflict of Interest Statement: The authors declare that the research was conducted in the absence of any commercial or financial relationships that could be construed as a potential conflict of interest.

Copyright (c) 2017 Ghequire, Kemland and De Mot. This is an open-access article distributed under the terms of the Creative Commons Attribution License (CC BY). The use, distribution or reproduction in other forums is permitted, provided the original author(s) or licensor are credited and that the original publication in this journal is cited, in accordance with accepted academic practice. No use, distribution or reproduction is permitted which does not comply with these terms. 